\title{
THE EFFICIENCY OF COMPARATIVE CAUSATION
}

\author{
Francesco Parisi \\ Email: parisi@umn.edu \\ University of Minnesota and University of Bologna \\ Department of Economics
}

\author{
Ram Singh
}

Email: ramsingh@econdse.org

Delhi School of Economics

University of Delhi

\section{Working Paper No. 179}

Centre for Development Economics

Department of Economics, Delhi School of Economics 


\title{
The Efficiency of Comparative Causation*
}

\author{
Francesco PARISI ${ }^{\dagger}$ and Ram SINGH ${ }^{\ddagger}$
}

June 27, 2009

\begin{abstract}
Comparative causation is the only tort regime that allows parties to share an accident loss in equilibrium. The sharing of an accident loss between a nonnegligent injurer and his nonnegligent victim spreads activity level and $R \& D$ incentives between prospective tortfeasors and their victims. This is an effect that is never observed under the other negligence and strict liability based regimes. In spite of these interesting attributes, the existing literature left open the question as to whether loss sharing was able to maintain optimal care incentives for both parties. In this paper, we address this unresolved issue in the literature, considering the efficiency of loss-sharing under comparative causation. JEL classification: K13, K32.

Keywords: torts, loss-sharing, negligence, strict liability, comparative causation.
\end{abstract}

\section{Introduction}

The law and economics literature has devoted extensive attention to the different negligence and strict liability regimes, with a wide array of formal economic models used to analyze the effect of alternative liability rules on the parties' incentives. ${ }^{1}$ In this literature it is shown that different liability regimes often produce similar incentives with respect to the parties' care. Traditional liability rules produce all-or-nothing allocations of the residual loss in equilibrium (the allocation of the loss when all parties adopt due care). Negligence and strict liability regimes, for example, by choosing substantially different allocations of the residual loss, produce substantially opposite incentives with respect to the parties' activity level and the R\&D incentives. ${ }^{2}$ Unlike its traditional counterparts, the rule of comparative causation allows a nonnegligent injurer and a

\footnotetext{
${ }^{*}$ The authors would like to thank Giuseppe Dari-Mattiacci, Vincy Fon, Barbara Luppi, Allan Feldman and TCA Anant for previous conversations on this topic.

${ }^{\dagger}$ University of Minnesota, Law School and University of Bologna, Department of Economics. Email: parisi@umn.edu

${ }^{\ddagger}$ Delhi School of Economics, University of Delhi. Email: ramsingh@econdse.org

${ }^{1}$ For example, see Polinsky (1989), Landes and Posner (1987), Shavell (1987), Miceli (1997), Jain and Singh (2002), etc.

${ }^{2}$ The victim bears the residual loss under all rules that use negligence as the criterion to impose primary liability (simple negligence, negligence with a defense of contributory negligence and negligence with a defense of comparative negligence). The injurer instead bears the entire residual loss under all rules that use strict liability as the basis for the primary liability (strict liability, strict liability with a defense of contributory negligence and strict liability with a defense of comparative negligence).
} 
nonnegligent victim to share an accident loss in equilibrium. The sharing of an accident loss spreads activity level and $R \& D$ incentives between the parties. This is an effect that is not reached by any of the conventional rules based on negligence or strict liability.

In a series of articles, negligence criterion based approach towards liability has been severely criticized. ${ }^{3}$ It has been argued that since negligence liability neglects the causal contribution of the parties involved, it does not form a convincing basis for the allocation of liability between non-negligent parties. Under standard negligence based liability rules, a party usually faces either full liability or no liability at all. For example, under the rule of negligence, an injurer has no liability if he is not negligent. However, his liability discontinuously jumps from zero to one-hundred percent, as soon as his care level falls below the due level of care. Under simple negligence, this is the case even if the victim has taken no care at all. Similar is the case under the rule of strict liability with the defense of contributory negligence. Under this rule, the victim becomes fully liable for the loss if his care level falls just below the due level of care, even if the injurer took no care at all. Besides these problematic discontinuities, traditional rules follow an all-or-nothing approach in the allocation of the loss when both parties are non-negligent, such that the entire accident loss is borne by just one party in equilibrium. As early as 1965, Guido Calabresi critically observed that negligence regimes only deter accidents that are caused through fault and ignore the value of deterring accidents that are faultless. Faultless accidents are those that should be expected when parties respond to incentives in equilibrium. Calabresi further suggested that the cost of faultless accidents could be divided pro rata among the activities involved. For example if a walker, a bicyclist and an automobile are all involved in an accident, the costs could be divided amongst these three activities on the basis of their causal contribution to the accident. This would imply assigning greater liability to activities that are statistically more likely to increase the probability or severity of an accident (Calabresi, 1965, p. 740-741). Calabresi (1996) returned to this issue lamenting that no consideration had been given to the idea of distributing an accident loss among a faultless tortfeasor and an innocent victim on the basis of the relative causal contribution of the parties to the loss. Calabresi's proposed criterion of apportionment of liability revived a forgotten idea which first advocated in 1625 by the Dutch legal scholar Hugo Grotius under the name of compensation principle, an idea that did not enjoy much acceptance by modern legal systems until recent years. Calabresi and Cooper (1996) explored the issue of comparative causation tracing the spread of comparative causation rules

\footnotetext{
${ }^{3}$ For criticisms of economic modeling of liability rules on various grounds see Grady (1989), Kahan (1989), Mark (1994), Burrow (1999), and Wright (1987). In addition, the argument goes, negligence rules are either inapplicable or unsatisfactory in cases where multiple causation is involved or where fault is not easy to establish (Strassfeld, 1992).
} 
in tort cases. They show that over the last 30 years US courts began favoring solutions based on comparative negligence over contributory negligence on equitable grounds and suggested that modern trends in case law favor the idea of an equitable apportionment of an accident loss also between faultless parties - an equitable apportionment that the criterion of comparative causation can deliver in equilibrium. Summarizing these ideas, the authors write: "The integration of non-fault notions into the splitting analysis under comparative negligence could ultimately lead us to compare non-fault with non-fault-comparative-nonnegligence, if you will. That is, there may be situations in which neither side was negligent, but each side could have done something to avoid the loss and did not. In these situations, too, we might want to split the loss. But we are, in fact, nowhere near ready to do that yet, across the board. And so where neither side is at fault, we still remain subject to all-or-nothing rules. In the absence of defendant fault, innocent plaintiffs bear the whole loss in most areas, while in so-called non-fault liability areas, defendants bear the entire loss where neither party is at fault" (Calabresi and Cooper, 1996, p. 877). The authors illustrate the trend toward comparative causation, suggesting that in areas that had typically been subjected to strict liability or negligence, there may be some desire to split the damages among faultless parties instead of having a legal rule in place that puts the entire burden of loss on either the plaintiff or defendant. An apportionment of liability in which parties bear an accident loss proportional to their causal contribution to the accident loss is indeed consistent with principles of equity and social insurance, which might require loss spreading between faultless parties (Honoré, 1997). A comparative causation rule could be justified on equitable grounds by arguing that it does not overly burden parties, inducing a loss sharing that shields both parties from the risk of facing the entire loss in equilibrium (Calabresi and Cooper, 1996, p. 878). As various studies have revealed, in recent years courts in many countries, including France, Germany, Japan and the United States have used causation-based apportionments of liability (see, e.g., Yoshihsa (1999), Grimley (2000) and Yu $(2000)){ }^{4}$

Following Calabresi and Cooper, Parisi and Fon (2005) have traced an intellectual history of the principle of comparative causation, considering some applications of the rule in historical and contemporary societies. The authors note that, despite its lineage in legal history, limited attention has been devoted among law and economics scholars to the efficiency properties of causation-

\footnotetext{
${ }^{4}$ As discussed in Parisi and Fon (2004), the implications and potential reach of this paradigm of liability are extensive. Several all-or-nothing criteria of liability might be reconsidered for more nuanced solutions. For example, as noted by Calabresi and Cooper (1996) adopting a rule of comparative causation might transform the use of proximate cause because a party's behavior, even though remote in time, may still have provided a causal contribution to the loss. Likewise, under joint and several liability a negligent co-defendant could be forced to pay the entire judgment. However, as Calabresi and Cooper (1996, p. 880-881) point out, with comparative causation, statistical causation could be used to apportion the loss between co-defendants.
} 
based allocations of liability. In a related paper Parisi and Fon (2004) have developed an economic model to identify the virtues and limits of the compensation principle, considering how such principle would perform when applied as a general and sole basis of liability, in the absence of other liability rules, and later extended the analysis to the case of a joint application of the principle within a negligence system. Parisi and Fon (2004) have studied the desirability or otherwise of comparative causation based liability, as an alternative to the negligence based liability. The paper has studied the issue in a general framework that allows the parties to choose care levels as well as activity levels. It has introduced and analyzed two new rules. The first rule is called the rule of pure comparative causation. Under this rule, parties bear accident loss in shares that are proportional to their causal contribution to the accident loss, regardless of whether at the time of the accident they were at fault or not. It is shown that under this rule, since each party bears only a fraction of the accident loss, there is an incentive for the parties to choose less than the socially optimal care levels and more than the socially optimal activity levels. That is, the rule of pure comparative causation induces neither efficient care levels nor efficient activity levels. The second rule considered by Parisi and Fon (2004) is called the rule of comparative causation under negligence. This rule mixes the essential features of traditional negligence criterion based rules and that of the rule of pure comparative causation. Under this new rule, a solely negligent party bears the entire accident loss. However, the accident loss is shared between the parties, when both parties are negligent or when both are non-negligent. In such cases, loss-sharing is done as under the rule of Pure comparative causation. ${ }^{5}$ This rule bring in an element of equity and reduces the magnitude of 'jumps' in liability of both parties. Under this rule, as a party reduces his care from being non-negligent to become negligent, his liability increases from partial-liability to full-liability and vice-versa; not from zero-liability to full-liability and viceversa. Kahan (1987), Van Wijck and Winters (2001), Singh (2007a and 2007b), Schweizer (2009), and Feldman and Singh (2009) have studied several different versions of 'causation-based liability'. The rules considered by these authors, however, are quite different from the principle of comparative causation. Moreover, analysis in these studies is restricted to only care levels; as activity levels are assumed to be constant. ${ }^{6}$ In spite of the recent interest in comparative causation regimes, the existing literature has thus far left open the question as to whether the possibility to share the loss in equilibrium undermines optimal care

\footnotetext{
${ }^{5}$ Proportional loss sharing also takes place under the rule of comparative negligence. However, under this rule, loss sharing takes place only when both parties are negligent; not when both parties are non-negligent. For an analysis of this rule see Schwartz, G. (1978), Landes and Posner (1980), Cooter and Ulen (1986), Haddock and Curran (1985), Rubinfeld (1987), and Rea (1987). For a critical review of some of these works see Liao and White (2002), and Bar-Gill and Ben-Shahar (2003).

${ }^{6}$ Assuming constant activity levels, efficiency properties of the rule of Comparative Causation Under Negligence are explored in Singh (2007 b).
} 
incentives for the parties.

In this paper, we address this unresolved issue in the literature, considering the efficiency of a rule of comparative causation under negligence. This rule is an elegant hybrid of negligence and causation-based strict liability, which allows loss-sharing in equilibrium. If it can induce an equilibrium in which both parties take due care, it would possess a highly desirable property of inducing both parties to mitigate their activity levels and at the same time ensure an equitable division of the accident loss when both parties are non-negligent. By inducing both parties to adopt efficient care as well mitigating their activity levels, this rule would have the unique virtue of being efficient as well as equitable.

The paper is structured as follows. Section 2 introduces notations, assumptions and the framework of analysis. In the interest of brevity, in the following we shall refer to the rule of comparative causation under negligence as "comparative causation" with no further qualification. The analysis is carried out in a framework that follows Parisi and Fon (2004), assuming that care levels as well as activity levels of the parties affect the causation of an accident and the expected loss in the event of an accident. We extend our framework allowing for a very general form of the causation function. ${ }^{7}$ In Section 3, we study the issue of existence of equilibria under the rule of comparative causation. In Section 4, we analyze the efficiency properties of the rule. We show that the rule of comparative causation possess some desirable properties. In an equilibrium under the rule both the parties will always choose at least the due level of care or more. Therefore, this rule induces at least efficient care as well as equitable distribution of accident loss. It does so for contexts with constant as well as variable activity levels. Since the residual loss is spread between the parties, also activity level incentives are spread between the parties, rather than being concentrated on one or the other party like in traditional negligence or strict liability regimes. ${ }^{8}$ Section 5 concludes with remarks on the analysis in the paper, observing that our results proves the conjecture made in Parisi and Fon (2004) that the principle of comparative causation can achieve equity and spread activity level incentives between the parties without diluting the parties' care level incentives.

\footnotetext{
${ }^{7}$ Apart from the principle of comparative causation, the nature of causal relation and its efficiency properties also warrant further research. As far as the formalization of individual inputs to the causation of an accident is concerned, the focus of the mainstream has been on only two forms of the causal relationship; namely, the cases of causal substitutes and causal complements. In the first case, the causal inputs of the parties are assumed to affect the causation of an accident additively while in the latter they are assumed to do so multiplicatively. However, as the literature suggests, the causal inputs of the parties can affect the total causation in several and complex ways including the above two. Therefore, there is need to allow for more general forms of total causation function.

${ }^{8}$ As well known, decoupling solutions aside, no liability rule can put the entire accident loss on both the parties simultaneously, and therefore no liability rule can achieve first-best activity level incentives for both parties.
} 


\section{A General Model of Comparative Causation}

We will work in the framework introduced in Parisi and Fon (2004) (hereafter $P \& F)$. That is, we consider accidents resulting from the interaction of two parties who are strangers to each other or otherwise unable to allocate the risk of accidents between themselves contractually. Both parties are assumed to be rational and risk-neutral. Each party's behavior potentially contributes to causing an accident. However, when an accident takes place, the entire loss falls on one party to be called the victim; the other party is called the injurer. Parties' choice of activity levels as well as care levels affect the causing of an accident. A parties contribution to causation of an accident increases with its activity level and decreases with its care level, and vice-versa. In other words, a party's contribution to the causation of an accident increases, if it increases its activity level or decreases its care level vice-versa. Parties' individual contributions to causation of an accident are referred to as causal inputs. Therefore, a party's causal input increases with an increase in its activity level, and decreases with an increase in its care level. Causation of an accident depends on the causal inputs of the parties involved. The elements contributing to the overall social cost of accident, are the cost of harm occasioned by an accident, the cost of care, and the cost of reducing the parties' activity levels.

Following the notation in $P \& F$, denote by:

$x$ care level for the injurer,

$y$ care level for the victim,

$z$ activity level for the injurer,

$u$ activity level for the victim,

$X$ the care choice set for the injurer,

$Y$ the care choice set for the victim,

$Z$ the activity choice set for the injurer,

$U$ the activity choice set for the victim,

$w$ the benefit function for the injurer,

$b$ the benefit function for the victim,

$D$ expected loss per unit of activity, $D \geq 0$,

$c^{I}$ the causal input of the injurer,

$c^{V}$ the causal input of the victim,

$C$ the total causation function,

$s$ the injurer's share in accident loss,

$t$ the victim's share in accident loss, such that $t=1-s$.

Assumptions:

(A1): $w$ is a function of $z$ and $x ; w=w(z, x)$. In particular, $w$ is a strictly 
increasing and concave function of $z$; and a strictly decreasing and weakly concave function of $x$ for all $z \in Z$. i.e., $w_{z}>0, w_{z z}<0$ with $\lim _{z \rightarrow \infty} w_{z}=0$; and $w_{x}<0, w_{x x} \leq 0$. Likewise,

(A2): $b$ is a function of $u$ and $y ; b=b(u, y) . b_{u}>0, b_{u u}<0$ with $\lim _{u \rightarrow \infty} b_{u}=$ 0 ; and $b_{y}<0, b_{y y} \leq 0$.

(A3): $D$ is a function of $x$ and $y ; D=D(x, y) . D \geq 0$. $D$ is a decreasing and convex function of care level of each party. That is, $D_{x}<0, D_{x x}>0$, $D_{y}<0$, and $D_{y y}>0$. Moreover, $D_{x y}>0$, i.e., care by parties are substitutes. As $D$ is expected loss per unit of activity, for given $z$ and $u$ total expected loss will be $z u D(x, y)$.

(A4): $c^{I}$ is a function of $z$ and $x ; c^{I}=c^{I}(z, x)$ such that $c_{z}^{I}>0, c_{z z}^{I}>0$, $c_{x}^{I}<0$ and $c_{x x}^{I}>0$.

(A5): $c^{V}$ is a function of $u$ and $y ; c^{V}=c^{V}(u, y)$ such that $c_{u}^{V}>0, c_{u u}^{V}>0$, $c_{y}^{V}<0$ and $c_{y y}^{V}>0$. Note that (A4) and (A5) imply that by increasing its activity level or reducing its care level, a party increases its contribution to the causing of an accident, i.e., makes the accident more likely, and vice-versa.

(A6): $C$, the total causation function, is an increasing function of both $c^{I}$ and $c^{V} ; C=C\left(c^{I}, c^{V}\right)$. Therefore, $C_{z}>0, C_{u}>0, C_{x}<0$ and $C_{y}<0$, etc follow immediately.

(A7): Social benefits from activity of a party are fully internalized by that party.

(A8): Social goal is to maximize the net social benefits from the activities of the parties; the net social benefits are equal to the total social benefits minus the total social costs of accident.

(A9): Benefit, cost, and causation functions are such that there is a unique set of values of $z, u, x$, and $y$, denoted by $\left(\left(z^{*}, x^{*}\right),\left(u^{*}, y^{*}\right)\right)$ that is socially optimal. In other words, the net social benefits are maximized, if the injurer chooses $z^{*}$ as his activity level and $x^{*}$ as his care level, and the victim chooses $u^{*}$ as his activity level and $y^{*}$ as his care level.

(A10): The legal due care standard for the injurer, wherever applicable (say under the simple rule of negligence), is set at $x^{*}$. Similarly, the legal negligence standard of care for the victim, wherever applicable (say under the rule of strict liability with defense of contributory negligence) is set at $y^{*}$.

It should be noted that the causation function, $C$, in (A6) is more general than in $P \& F$ wherein only two separate forms of $C\left(c^{I}(z, x), c^{V}(u, y)\right)$ are considered; namely when $C\left(c^{I}(z, x), c^{V}(u, y)\right)=c^{I}(z, x) . c^{V}(u, y)$, and when $C\left(c^{I}(z, x), c^{V}(u, y)\right)=c^{I}(z, x)+c^{V}(u, y)$. The first formulation above corresponds to the case of causal complements, while the second represents the case of causal substitutes. Although in some cases causal inputs affect causation of 
an accident additively (i.e., causal substitutes) or multiplicatively (i.e., causal complements), in real life situations the parties are likely to affect the causation of an accident in several different ways, in which causation follows a more complex mix thereof (Parisi and Fon 2004; Landes and Posner, 1983). ${ }^{9}$ Therefore, in this paper, we allow a general form of the causation function, subject to assumption (A6). The limiting cases of causal complements and causal substitutes can therefore be viewed as special cases of our general function $C$. The relevant results for these special cases can be found out simply by substituting any of the two explicit forms in our general causation function.

The social objective is to maximize the net social benefits from the activities. Therefore, the social optimization problem is given by: ${ }^{10}$

$$
\max _{z, x, u, y}\left\{w(z, x)+b(u, y)-C\left(c^{I}(z, x), c^{V}(u, y)\right) z u D(x, y)\right\} .
$$

In view of $(\mathrm{A} 9),\left(\left(z^{*}, x^{*}\right),\left(u^{*}, y^{*}\right)\right)$ uniquely solves this problem.

A liability rule sets due care standards for both the parties. Also, depending on care and activity levels, it determines the shares in which accident loss is to be borne by the parties.

Formally, a liability rule can be considered as a rule or a mechanism that determines the proportions in which the victim and the injurer bear the accident loss, as a function of their care and activity levels. That is, given the choice of $z$ and $x$ made by the injurer and of $u$ and $y$ made by the victim, a liability rule uniquely determines the injurer's share, $s(z, x, u, y)$, and the victim's share, $t(z, x, u, y)$, of the accident loss. ${ }^{11}$ For example, under the rule of pure comparative causation ${ }^{12}$

$$
s(z, x, u, y)=\frac{c^{I}(z, x)}{c^{I}(z, x)+c^{V}(u, y)},
$$

and

$$
t(z, x, u, y)=\frac{c^{V}(u, y)}{c^{I}(z, x)+c^{V}(u, y)} .
$$

The choice of care and activity levels by one party depends on the liability rule in force, as well as on the care and activity levels chosen by the other party.

\footnotetext{
${ }^{9}$ Also see Rizzo and Arnold (1980 and 1986), Kaye and Aickin (1984), Wright (1985), and Kruskal (1986).

${ }^{10} \mathrm{This}$ formulation of social optimization problem is as in $P \& F$. Second order conditions are assumed to be fulfilled.

${ }^{11}$ It should be noted that in the standard literature, these share depend only on the care levels of the parties involved. Here, we have assumed causation of an accident to depend on care as well as activity levels, and we are concerned with comparative causation liability which requires loss sharing based on individual causal contributions. Therefore, in the present framework these shares depend on care as well as activity levels. A more precise specification of liability shares is provided below.

${ }^{12}$ See Parisi and Fon (2004).
} 
For any given pair $(u, y)$ chosen by the victim, the prospective injurer being rational and risk-neutral will choose a pair $(z, x)$ that maximizes his expected payoff. In other words, given that $(u, y) \in U \times Y$ is chosen by the victim, the problem facing the injurer becomes

$$
\max _{z, x}\left\{w(z, x)-s(z, x, u, y) C\left(c^{I}(z, x), c^{V}(u, y)\right) z u D(x, y)\right\} .
$$

Likewise, given that $(z, x) \in Z \times X$ is chosen by the injurer, the problem facing the victim becomes

$$
\max _{u, y}\left\{b(u, y)-t(z, x, u, y) C\left(c^{I}(z, x), c^{V}(u, y)\right) z u D(x, y)\right\}
$$

where $s(z, x, u, y)$ and $t(z, x, u, y)$ are determined by the relevant liability rule, but are such that $s+t=1 .{ }^{13}$

Now, we are all set to introduce the rule of comparative causation. Under this rule, when a party is found solely negligent, it bears the entire accident loss. Accident loss is shared between the parties only in cases where parties are either both negligent or when both are non-negligent. ${ }^{14}$ In such cases, the loss-sharing is done according to the criterion discussed above under the rule of pure comparative causation. Formally, under this rule, given $(u, y) \in U \times Y$ is chosen by the victim, the problem faced by the injurer is given by the following:

$$
\max _{z, x}\left\{\begin{array}{l}
w(z, x) \quad \text { if } x \geq x^{*} \text { and } y<y^{*} ; \\
w(z, x)-\frac{c^{I}(z, x)}{c^{I}(z, x)+c^{V}(u, y)} C\left(c^{I}(z, x), c^{V}(u, y)\right) z u D(x, y) \text { if } x \geq x^{*} \text { and } y \geq y^{*}, \\
\text { or if } x<x^{*} \text { and } y<y^{*} ; \\
w(z, x)-C\left(c^{I}(z, x), c^{V}(u, y)\right) z u D(x, y) \quad \text { if } x<x^{*} \text { and } y \geq y^{*} .
\end{array}\right.
$$

Similarly, given that $(z, x) \in Z \times X$ is chosen by the injurer, the problem facing the victim is:

$$
\max _{u, y}\left\{\begin{array}{l}
b(u, y) \quad \text { if } x<x^{*} \text { and } y \geq y^{*} ; \\
b(u, y)-\frac{c^{V}(u, y)}{c^{I}(z, x)+c^{V}(u, y)} C\left(c^{I}(z, x), c^{V}(u, y)\right) z u D(x, y) \text { if } x \geq x^{*} \text { and } y \geq y^{*}, \\
\text { or if } x<x^{*} \text { and } y<y^{*} ; \\
b(u, y)-C\left(c^{I}(z, x), c^{V}(u, y)\right) z u D(x, y) \quad \text { if } x \geq x^{*} \text { and } y<y^{*} .
\end{array}\right.
$$

\footnotetext{
${ }^{13}$ Hence, any form of decoupling (with $s+t>1$ ) and of social insurance (with $s+t<1$ ) are excluded.

${ }^{14}$ As explained above, this rule corresponds to the rule of comparative causation discussed in Parisi and Fon (2004) under the name of "comparative causation under negligence."
} 
Let an equilibrium under the rule of comparative causation be denoted by $((\bar{z}, \bar{x}),(\bar{u}, \bar{y}))$. In view of the above description of the rule, it is easy to see that the liability shares $s$ and $t$ depend on care as well as activity levels only when parties are either both negligent or both vigilant. In the remaining cases, namely when one party is negligent and the other is diligent, liability shares are essentially functions of only care levels.

\section{$3 \quad$ Equilibria}

In this section, we will study the nature of equilibria under the rule of comparative causation. Among other things, we will find out how the values $((\bar{z}, \bar{x}),(\bar{u}, \bar{y}))$ compare with the socially optimal profile of care and activity levels derived above, $\left(\left(z^{*}, x^{*}\right),\left(u^{*}, y^{*}\right)\right)$. For the time being assume that under the rule at least one equilibrium exists. To start with, we explore the implications of the following property that is a common feature of negligence-based rules.

Property (P1): A non-negligent party has no liability, if the other party is negligent. That is, the entire accident loss is borne by the negligent party if the other party happens to be diligent.

First, we show that under a liability rule that satisfies property (P1), the parties cannot both be negligent in a N.E., no matter how the liability is assigned when both parties are negligent. In other words, in any Nash equilibrium, $x<x^{*}$ and $y<y^{*}$ can never hold.

To see why, take any set of values, say $((z, x),(u, y))$ such that $x<x^{*}$ and $y<y^{*}$. Suppose, the injurer chooses $(z, x)$ and the victim chooses $(u, y)$. At $((z, x),(u, y))$, let $s(z, x, u, y)$ be the injurer's share of loss, where $0 \leq$ $s(z, x, u, y) \leq 1$. So, $t(z, x, u, y)=1-s(z, x, u, y)$. As a result, suppressing the arguments of $s$ and $t$, at $((z, x),(u, y))$, the payoff of the victim is

$$
b(u, y)-t C\left(c^{I}(z, x), c^{V}(u, y)\right) z u D(x, y) .
$$

On the other hand, given that $(z, x)$ is chosen by the injurer, if the victim instead chooses $\left(u^{*}, y^{*}\right)$, then the injurer will be solely negligent. In that case, in view of (P1), the injurer's liability will be full and that of the victim will be none. Therefore, given that $(z, x)$ is chosen by the injurer, if the victim chooses $\left(u^{*}, y^{*}\right)$, his payoff will be $b\left(u^{*}, y^{*}\right)$. Similarly, at $((z, x),(u, y))$ the payoff of the injurer is

$$
w(z, x)-s C\left(c^{I}(z, x), c^{V}(u, y)\right) z u D(x, y) .
$$

But, given that $(u, y)$ is chosen by the victim, if the injurer chooses instead 
$\left(z^{*}, x^{*}\right)$, his payoff will be $w\left(z^{*}, x^{*}\right)$. At $((z, x),(u, y))$ if

$$
w\left(z^{*}, x^{*}\right)>w(z, x)-s C\left(c^{I}(z, x), c^{V}(u, y)\right) z u D(x, y)
$$

holds, then a unilateral deviation by the injurer to $\left(z^{*}, x^{*}\right)$ is strictly preferable. In that case, $((z, x),(u, y))$ cannot be a N.E. Thus, if $((z, x),(u, y))$ is a N.E., then a unilateral deviation by the injurer to $\left(z^{*}, x^{*}\right)$ cannot be strictly preferable. Therefore, assume that

$$
w(z, x)-s C\left(c^{I}(z, x), c^{V}(u, y)\right) z u D(x, y) \geq w\left(z^{*}, x^{*}\right)
$$

Since $((z, x),(u, y)) \neq\left(\left(z^{*}, x^{*}\right),\left(u^{*}, y^{*}\right)\right)$, by assumption, we know that

$$
\begin{aligned}
w\left(z^{*}, x^{*}\right) & +b\left(u^{*}, y^{*}\right)-C\left(c^{I}\left(z^{*}, x^{*}\right), c^{V}\left(u^{*}, y^{*}\right)\right) z^{*} u^{*} D\left(x^{*}, y^{*}\right) \\
& >w(z, x)+b(u, y)-C\left(c^{I}(z, x), c^{V}(u, y)\right) z u D(x, y) .
\end{aligned}
$$

Subtracting $w\left(z^{*}, x^{*}\right)$ from the LHS and $w(z, x)-s C\left(c^{I}(z, x), c^{V}(u, y)\right) z u D(x, y)$ from the RHS of (2), in view of (1), we get

$$
\begin{aligned}
b\left(u^{*}, y^{*}\right) & >b(u, y)+C\left(c^{I}\left(z^{*}, x^{*}\right), c^{V}\left(u^{*}, y^{*}\right)\right) z^{*} u^{*} D\left(x^{*}, y^{*}\right) \\
& -t C\left(c^{I}(z, x), c^{V}(u, y)\right) z u D(x, y) .
\end{aligned}
$$

Now, since by assumption $C\left(c^{I}\left(z^{*}, x^{*}\right), c^{V}\left(u^{*}, y^{*}\right)\right) z^{*} u^{*} D\left(x^{*}, y^{*}\right) \geq 0$, from (3) we have

$$
b\left(u^{*}, y^{*}\right)>b(u, y)-t C\left(c^{I}(z, x), c^{V}(u, y)\right) z u D(x, y) .
$$

That is, given $(z, x)$ is chosen by the injurer, payoff of the victim is strictly greater if he chooses $\left(u^{*}, y^{*}\right)$ rather than $(u, y)$, i.e., the victim is better off adopting $\left(u^{*}, y^{*}\right)$ rather than $(u, y)$. Again, $((z, x),(u, y))$ cannot be a N.E.

In other words, under a liability rule satisfying $(\mathrm{P} 1)$, from any $((z, x),(u, y))$ such that $x<x^{*} \& y<y^{*}$, either the injurer will find unilaterally deviation to $\left(z^{*}, x^{*}\right)$ preferable, or the victim will find unilaterally deviation to $\left(u^{*}, y^{*}\right)$ preferable. Hence, we have the following result: If a liability rule satisfies property $(\mathrm{P} 1)$, then

$$
\left(\forall((z, x),(u, y))\left[x<x^{*} \& y<y^{*} \Rightarrow((z, x),(u, y)) \text { cannot be a N.E. }\right]\right.
$$


It is interesting to note that all of the negligence criterion based rules discussed in the literature (e.g., the rule of negligence, the rule of negligence with the defense of contributory negligence, the rule of strict liability with the defense of contributory negligence) satisfy property (P1). Therefore, under any of these rules there cannot be an equilibrium in which both the parties are negligent.

Now, let us return to the rule of comparative causation. Equilibrium under the rule is denoted by $((\bar{z}, \bar{x}),(\bar{u}, \bar{y}))$. As we stated earlier, we want to find out how $((\bar{z}, \bar{x}),(\bar{u}, \bar{y}))$ compares with the socially optimal profile of activity and care levels, i.e., with $\left(\left(z^{*}, x^{*}\right),\left(u^{*}, y^{*}\right)\right)$.

As it turns out, the rule of comparative causation satisfies Property (P1). Therefore, in equilibrium $\bar{x}<x^{*}$ and $\bar{x}<y^{*}$ can never hold, i.e., under the rule of comparative causation, there cannot be a N.E. in which both parties choose to be negligent with respect to care levels.

In fact, Property (P1) enables us to make further deductions about the behavior of the parties with respect to their choice of care levels. Suppose a liability rule satisfies Property $(\mathrm{P} 1)$. When $x \geq x^{*}$ and $y<y^{*}$, the victim is solely negligent. In such an event, due to Property (P1), the injurer has no liability. So, for given $z$ his payoff is $w(z, x)$. Note that $w(z, x)$ increases as care level $x$ decreases. Therefore, regardless of the $z$ chosen by him whenever $x>x^{*}$, the injurer can increase his payoff simply by reducing $x$ until he reaches $x^{*}$. This means that if the victim has chosen some $y$ such that $y<y^{*}$, the injurer is always better off adopting $x^{*}$ rather than any $x>x^{*}$, regardless of what $z$ is. As a result, any set of values $((z, x),(u, y))$, such that $x>x^{*} \& y<y^{*}$, cannot be a N.E. Similarly, under a rule that satisfies Property (P1), a set of values $((z, x),(u, y))$, such that $x<x^{*} \& y>y^{*}$, cannot be a N.E. In this case, the victim can increase his payoff by reducing $y$ until he reaches $y^{*}$. Therefore, in view of the fact that the rule of comparative causation satisfies Property (P1), we have the following result for the rule: For all $((z, x),(u, y))$

$\left[\left(x>x^{*} \& y<y^{*}\right)\right.$ or $\left.\left(x<x^{*} \& y>y^{*}\right)\right] \Rightarrow((z, x),(u, y))$ cannot be a N.E.

In the following we will show that under the rule of comparative causation, in equilibrium no party would want to be negligent. For the ease of exposition, let

$z_{p}^{*}=$ the activity level of the injurer that maximizes $w(z, x)$ when $x=x^{*}$. 
$u_{p}^{*}=$ the activity level of the victim that maximizes $b(u, y)$ when $y=y^{*}$.

That is, $z_{p}^{*}$ is the optimum activity level for the injurer when he simply chooses $x^{*}$ as care level but does not bear the accident costs at all. Likewise, for $u_{p}^{*}$. It is easy to show that $z_{p}^{*}>z^{*}$ and $u_{p}^{*}>u^{*}$. That is, if the injurer can avoid liability simply by adopting due care $x^{*}$ his activity level will be excessive. Similarly, the victim's activity level will be excessive, if he can avoid liability simply by adopting due care $y^{*}$.

Remark: When a liability rule satisfies Property (P1), in the region of $x \geq x^{*}$ and $y<y^{*}$, the injurer's payoff is $w(z, x)$. But $w(z, x)$ is uniquely maximized at $\left(z_{p}^{*}, x^{*}\right)$. Therefore, under a liability rule that satisfies Property (P1), when $x \geq x^{*}$ and $y<y^{*}$, a set of values $((z, x),(u, y))$ can be a N.E. only if $(z, x)=\left(z_{p}^{*}, x^{*}\right)$; if $(z, x)$ is different from $\left(z_{p}^{*}, x^{*}\right)$, the injurer can increase his payoff by deviating to $\left(z_{p}^{*}, x^{*}\right)$. Clearly, such deviation should not be possible in an equilibrium. Similarly, under a rule satisfying Property (P1), a set of values $((z, x),(u, y))$, where $x<x^{*}$ and $y \geq y^{*}$, can be a N.E. only if $(u, y)=\left(u_{p}^{*}, y^{*}\right)$.

Now we are ready to state and prove our main result about the nature of equilibria under comparative causation: A set of values $((z, x),(u, y))$ can be a N.E. under the rule only if $x \geq x^{*}$ and $y \geq y^{*}$. Formally,

Proposition 1 Let $((\bar{z}, \bar{x}),(\bar{u}, \bar{y}))$ be a N.E. under the rule of comparative causation. Then, $\bar{x} \geq x^{*}$ and $\bar{y} \geq y^{*}$.

A formal proof is provided in the Appendix. Informal argument is as follows. In view of the above, a set of values $((z, x),(u, y))$ cannot be a N.E. if $x<x^{*}$ and $y<y^{*}$, or if $x>x^{*}$ and $y<y^{*}$, or if $x<x^{*}$ and $y>y^{*}$. Therefore, to prove the claim, it is sufficient to show that under the rule, a set of values $((z, x),(u, y))$, such that $x=x^{*}$ and $y<y^{*}$, or $x<x^{*}$ and $y=y^{*}$, cannot be a N.E.

When $y=y^{*}$ and $x<x^{*}$, the injurer is the solely negligent party. Therefore, the victim's liability is zero. This means that the victim has strong incentives to engage in an excessive level of activity. The excessive activity on the part of the victim further increases the costs of accident, and it is the injurer who bears the entire cost. Therefore, in order to decrease the accident costs, a solely negligent injurer has incentive to increase his care level. In addition, excessive activity level of the victim enhances the productivity of the injurer's care, providing him with additional incentives to take even greater care. Indeed, as the formal argument shows the injurer does not want to take care that is less than $x^{*}$. An 
analogous argument shows that a set of values $((z, x),(u, y))$, where $x=x^{*}$ and $y<y^{*}$, cannot be a N.E.

Therefore, we have proved that an equilibrium under the rule of comparative causation will have at least the due care levels chosen by both the parties. Moreover, under certain conditions it is possible to prove that there will be a N.E. in the domain where both parties take due care. ${ }^{15}$ Unfortunately, without imposing more structure of the functional forms, we cannot make a similar claim with respect to the equilibrium choice of activity levels by parties.

\section{The Virtues of Comparative Causation}

By now we know that the rule of comparative causation induces both parties to be diligent. That is, under the rule, to be diligent is a dominant strategy for each party. In this section, we show that the rule of comparative causation has some additional interesting effects on the parties' activity levels that are not observed under any other conventional liability rule. These effects may be desirable or undesirable according to the circumstances of the case.

Let us start by anticipating that comparative causation, like all conventional liability rules, is unable to create optimal activity level incentives for both parties. Under the rule, the profile of efficient care and activity levels for both parties is not an equilibrium.

Proposition 2 Under the rule of comparative causation, $\left(\left(z^{*}, x^{*}\right),\left(u^{*}, y^{*}\right)\right)$ is not a N.E.

A formal proof is provided in the Appendix. The rule of comparative causation cannot create an optimal care and activity level incentives, for any arbitrary form of causation function. This is an inevitable result, since under comparative causation the residual loss is never borne by both parties in full. It is interesting, however, to note that, unlike any other known liability rule, both parties partially internalize the accident loss in equilibrium. This produces two important effects: (i) spreading the activity level incentives between the parties, rather than concentrating them on one or the other party, and (ii) augmenting the care incentives for one or both parties. This is due to the fact that, since both parties face a share of the accident loss in equilibrium, they will have incentives to mitigate their liability exposure by decreasing their level of activity and increasing their care level.

To prove the latter portion of this claim, we can consider an example wherein activity levels are constant, and where parties can choose only care levels. Since

${ }^{15}$ The existence of Nash equilibria follows from a result in game theory. For details see Singh (2006). 
accident contexts with constant activity levels are special a case of contexts with variable activity levels, this illustration will show the effect of the comparative causation rule on the parties' care incentives. Here is one such example.

Suppose activity levels are fixed at 1, i.e., suppose $z=1=u$ are given. In such a context, $c^{I}$ is a function of $x$ only, and $c^{V}$ is a function of $y$ only. Moreover, the standard social optimization problem can be written as

$$
\min _{(x, y) \in X \times Y}\left\{x+y+C\left(c^{I}(x), c^{V}(x)\right) D(x, y)\right\} .
$$

Also, the rule of comparative causation can be defined as follows: ${ }^{16}$

$$
\begin{gathered}
x \geq x^{*} \& y \geq y^{*} \Rightarrow\left[s(x, y)=\frac{c^{I}(x)}{c^{I}(x)+c^{V}(y)} \& t(x, y)=\frac{c^{V}(y)}{c^{I}(x)+c^{V}(y)}\right] \\
x<x^{*} \& y<y^{*} \Rightarrow\left[s(x, y)=\frac{c^{I}(x)}{c^{I}(x)+c^{V}(y)} \& t(x, y)=\frac{c^{V}(y)}{c^{I}(x)+c^{V}(y)}\right] ; \\
x \geq x^{*} \& y<y^{*} \Rightarrow[s(x, y)=0 \& t(x, y)=1] ; \\
x<x^{*} \& y \geq y^{*} \Rightarrow[s(x, y)=1 \& t(x, y)=0] .
\end{gathered}
$$

For further simplicity assume that $D(x, y)$ is constant. So, we simply write it as $D$. Also, let $C\left(c^{I}(x), c^{V}(x)\right)=\left[c^{I}(x)+c^{V}(x)\right]^{\frac{1}{2}}$. In this simple setting, the social optimization problem can be rewritten as

$$
\min _{(x, y) \in X \times Y}\left\{x+y+\sqrt{c^{I}(x)+c^{V}(y)} \cdot D\right\} .
$$

Therefore, $x^{*}$ and $y^{*}$ solve the following first order conditions:

$$
\begin{aligned}
& 1+\frac{c_{x}^{I}(x) D}{2 \sqrt{c^{I}(x)+c^{V}\left(y^{*}\right)}}=0 \\
& 1+\frac{c_{y}^{V}(y) D}{2 \sqrt{c^{I}\left(x^{*}\right)+c^{V}(y)}}=0
\end{aligned}
$$

respectively.

Note that when $x \geq x^{*}$ and $y \geq y^{*}$, total costs of the injurer are given by

$$
x+\frac{c^{I}(x)}{c^{I}(x)+c^{V}(y)} \sqrt{c^{I}(x)+c^{V}(y)} \text { D, i.e., } \quad x+\frac{c^{I}(x)}{\sqrt{c^{I}(x)+c^{V}(y)}} D .
$$

Now, suppose the injurer has chosen $x^{*}$ and the victim has chosen $y^{*}$. Given $y^{*}$ chosen by the victim, consider a marginal increase in care from $x^{*}$ by the

\footnotetext{
${ }^{16}$ For more on the efficiency of 'comparative causation' when activity levels are constant, see Singh (2007)
} 
injurer. At $x^{*}$, the change in the total costs of the injurer caused by marginal increase in care is equal to $\left.\frac{d}{d x}\left(x+\frac{c^{I}(x)}{\sqrt{c^{I}(x)+c^{V}\left(y^{*}\right)}} D\right)\right|_{x=x^{*}}$, i.e., equal to

$$
1+\frac{c_{x}^{I}\left(x^{*}\right) D}{\sqrt{c^{I}\left(x^{*}\right)+c^{V}\left(y^{*}\right)}}-\frac{c_{x}^{I}\left(x^{*}\right) c^{I}\left(x^{*}\right) D}{2\left[c^{I}\left(x^{*}\right)+c^{V}\left(y^{*}\right)\right]^{\frac{3}{2}}} .
$$

From (4), given $y^{*}$ chosen by the victim, at $x^{*}$, we have $1=-\frac{c_{x}^{I}\left(x^{*}\right) D}{2 \sqrt{c^{I}\left(x^{*}\right)+c^{V}\left(y^{*}\right)}}$. So, (6) can be rewritten as

$$
-\frac{c_{x}^{I}\left(x^{*}\right) D}{2 \sqrt{c^{I}\left(x^{*}\right)+c^{V}\left(y^{*}\right)}}+\frac{c_{x}^{I}\left(x^{*}\right) D}{\sqrt{c^{I}\left(x^{*}\right)+c^{V}\left(y^{*}\right)}}-\frac{c_{x}^{I}\left(x^{*}\right) c^{I}\left(x^{*}\right) D}{2\left[c^{I}\left(x^{*}\right)+c^{V}\left(y^{*}\right)\right]^{\frac{3}{2}}}, \text { i.e, }
$$

as

$$
\frac{c_{x}^{I}\left(x^{*}\right)}{2 \sqrt{c^{I}\left(x^{*}\right)+c^{V}\left(y^{*}\right)}}\left[1-\frac{c^{I}\left(x^{*}\right)}{\left[c^{I}\left(x^{*}\right)+c^{V}\left(y^{*}\right)\right]}\right] D .
$$

However, since $c_{x}^{I}(x)<0, C\left(c^{I}(x), c^{V}(y)\right)>0$ always, and $c^{I}\left(x^{*}\right)<\left[c^{I}\left(x^{*}\right)+\right.$ $\left.c^{V}\left(y^{*}\right)\right]$, therefore, we have

$$
\frac{c_{x}^{I}\left(x^{*}\right)}{2 \sqrt{c^{I}\left(x^{*}\right)+c^{V}\left(y^{*}\right)}}\left[1-\frac{c^{I}\left(x^{*}\right)}{\left[c^{I}\left(x^{*}\right)+c^{V}\left(y^{*}\right)\right]}\right] D<0 .
$$

That is, the injurer can decrease his total costs by increasing his care level beyond $x^{*}$. Hence, $\left(x^{*}, y^{*}\right)$ is not a N.E. under the rule. That is, the rule of comparative causation may lead to excessive care levels. This possible distortion of care incentives may be useful to compensate for court errors and could be avoided by allowing the shares of causation to be apportioned exclusively on the basis of activity levels, rather than care levels, along the idea originally set by Calabresi (1996).

The effect of comparative causation on the parties' activity level incentives is instead worthy of attention. It is in this dimension that the virtues (and possible limits) of the criterion of comparative causation lie. Comparative causation leads both parties to face a share of the accident loss in equilibrium. This spreads the activity level incentives between them, such that both parties will face (partial) incentives to mitigate their liability exposure by decreasing their level of activity. This is an effect that, decoupling solutions apart, no standard liability rule can generate. The fact that the parties face only partial activity level incentives is inevitable since it is impossible to put the entire accident loss on both the parties at the same time. As a result, no standard liability rule can achieve the first best activity levels for both parties. Moreover, the above shown inefficiency of the rule of comparative causation for a constant activity level accident context is attributable to the choice of specific functional form 
of the causation function. For the standard cases of causal complements and causal substitutes, the rule is efficient when activity levels are constant (See Singh 2007 b).

This unveils some of the virtues and desirable properties of the rule of comparative causation. Proposition 1 shows that in an equilibrium under the rule, both the parties will always choose at least the due level of care or more. We have shown this for variable activity level accident contexts. It is easy to prove a similar claim for constant activity levels accident context as well. This means that the rule creates incentives for both the parties to be diligent. Recall that when both the parties have opted for at least the due level of care, under the rule the accident loss is apportioned between the parties in proportion to their causal contributions. Therefore, this rule induces at least the efficient care by both the parties as well as equitable distribution of accident loss among them. It does so for contexts with constant as well as variable activity levels. The sharing of the accident loss between a nonnegligent injurer and his nonnegligent victim spreads activity level and R\&D incentives between prospective tortfeasors and their victims. As a result, both parties have incentives to moderate their activity levels and increase R\&D so as to reduce the expected accident loss. This is an effect that is never observed under the other negligence and strict liability based regimes. It is this attribute of the rule of comparative causation that sets it apart.

\section{Concluding Remarks}

The principle of comparative causation has gained attention in the recent law and economics literature. However, its implications in terms of the nature of equilibria it generates and their efficiency properties have remained understudied. The results of this paper have contributed to a better understanding of the effects of comparative causation on the parties' care and activity level incentives. The analysis has been carried out in a very general framework. We have assumed that care levels as well as activity levels of the parties may affect the causation of accident and the expected loss in the event of accident. Moreover, we have extended the conventional framework by adopting a very general causation function. We have provided a formal proof of the conjecture made in Parisi and Fon (2004) that the principle of comparative causation can achieve an equitable loss-sharing between non-negligent parties, without diluting the parties' care incentives.

The rule of comparative causation combines essential elements of the negligence regimes with the loss-spreading function of comparative causation. We 
have shown that in a comparative causation regime, both parties adopt a level of care that is at least as high as the due level of care. That is the rule can ensure diligence by both parties. When causation can be affected by care levels, the rule can however have an overshooting effect, leading to the adoption of a care level that exceeds the due level. This is an interesting result, since conventional wisdom would instead suggest that loss-spreading in equilibrium would lead to an undershooting effect, diluting rather than exacerbating the parties' care incentives. Therefore, comparative causation induces diligent care as well as equitable distribution of loss among the parties involved in an accident. Moreover, it does so for contexts with constant as well as with variable activity levels.

The effects of comparative causation are particularly interesting with respect to the parties' activity level incentives. Comparative causation induces both parties to internalize a positive share of the social cost and benefits of their care and activity level in equilibrium, spreading the residual incentives to control activity levels between both parties. Whether these peculiar features of the comparative causation regimes are desirable in real life contexts, depends on a variety of factors. The findings of this paper will hopefully serve as a basis for future research, and for a systematic assessment of the overall performance of the comparative causation rule, in consideration of the parameters of the accident problem.

\section{APPENDIX}

\section{Proof of Proposition 1:}

First of all, note that the assumption that $\left(\left(z^{*}, x^{*}\right),\left(u^{*}, y^{*}\right)\right)$ uniquely solves the social optimization problem implies the following:

$\left(z^{*}, x^{*}\right)$ uniquely solves

$$
\max _{z, x}\left\{w(z, x)-C\left(c^{I}(z, x), c^{V}\left(u^{*}, y^{*}\right)\right) z u^{*} D\left(x, y^{*}\right)\right\} .
$$

That is, $z^{*}$ and $x^{*}$ simultaneously solve (7) and (8).

$$
\begin{gathered}
w_{z}(z, x)=\left[C_{z}\left(c^{I}(z, x), c^{V}\left(u^{*}, y^{*}\right)\right) z+C\left(c^{I}(z, x), c^{V}\left(u^{*}, y^{*}\right)\right)\right] u^{*} D\left(x, y^{*}\right) \\
\begin{aligned}
w_{x}(z, x) & =\left[C_{x}\left(c^{I}(z, x), c^{V}\left(u^{*}, y^{*}\right)\right) D\left(x, y^{*}\right)\right. \\
& \left.+C\left(c^{I}(z, x), c^{V}\left(u^{*}, y^{*}\right)\right) D_{x}\left(x, y^{*}\right)\right] z u^{*} .
\end{aligned}
\end{gathered}
$$


More specifically, $z^{*}$ solves (9):

$$
\begin{aligned}
w_{z}\left(z, x^{*}\right) & =\left[C_{z}\left(c^{I}\left(z, x^{*}\right), c^{V}\left(u^{*}, y^{*}\right)\right) z\right. \\
& \left.+C\left(c^{I}\left(z, x^{*}\right), c^{V}\left(u^{*}, y^{*}\right)\right)\right] u^{*} D\left(x^{*}, y^{*}\right) .
\end{aligned}
$$

Similarly, $\left(u^{*}, y^{*}\right)$ uniquely solves

$$
\max _{u, y}\left\{b(u, y)-C\left(c^{I}\left(z^{*}, x^{*}\right), c^{V}(u, y)\right) z^{*} u D\left(x^{*}, y\right)\right\}
$$

That is, $u^{*}$ and $y^{*}$ simultaneously solve (10) and (11).

$$
\begin{aligned}
b_{u}(u, y) & =\left[C_{u}\left(c^{I}\left(z^{*}, x^{*}\right), c^{V}(u, y)\right) u\right. \\
& \left.+C\left(c^{I}\left(z^{*}, x^{*}\right), c^{V}(u, y)\right)\right] z^{*} D\left(x^{*}, y\right) . \\
b_{y}(u, y) & =\left[C_{y}\left(c^{I}\left(z^{*}, x^{*}\right), c^{V}(u, y)\right) D\left(x^{*}, y\right)\right. \\
& \left.+C\left(c^{I}\left(z^{*}, x^{*}\right), c^{V}(u, y)\right) D_{y}\left(x^{*}, y\right)\right] z^{*} u .
\end{aligned}
$$

Also note that, in view of the arguments made in the text, to prove the claim, it is sufficient to show that under the rule, a set of values $((z, x),(u, y))$ such that $x=x^{*}$ and $y<y^{*}$, or $x<x^{*}$ and $y=y^{*}$ cannot be a N.E.

For the sake of argument, let us assume the contrary. That is, assume that a set of values $((z, x),(u, y))$, where $x<x^{*}$ and $y=y^{*}$, is a N.E. In view of the Remark made in the text, the set of values $((z, x),(u, y))$, such that $x<x^{*}$ and $y \geq y^{*}$, can be a N.E. only if $y=y^{*}$ and $u=u_{p}^{*}$. Therefore, the set of values $((z, x),(u, y))$, such that $x<x^{*}$ and $y \geq y^{*}$, can be a N.E. only if $((z, x),(u, y))=\left((z, x),\left(u_{p}^{*}, y^{*}\right)\right)$.

Now, let $\left(u_{p}^{*}, y^{*}\right)$ be chosen by the victim. Since at $x<x^{*}$ the injurer is solely negligent, under the rule he is fully liable. Therefore, when it is given that the victim has chosen $\left(u_{p}^{*}, y^{*}\right)$, in the region wherein $x<x^{*}$, the injurer's optimization problem is

$$
\max _{z, x}\left\{w(z, x)-C\left(c^{I}(z, x), c^{V}\left(u_{p}^{*}, y^{*}\right)\right) z u_{p}^{*} D\left(x, y^{*}\right)\right\} .
$$

In particular, when $x<x^{*}$, the optimum $z$ will solve 


$$
\begin{aligned}
w_{z}(z, x) & =\left[C_{z}\left(c^{I}(z, x), c^{V}\left(u_{p}^{*}, y^{*}\right)\right) z\right. \\
& \left.+C\left(c^{I}(z, x), c^{V}\left(u_{p}^{*}, y^{*}\right)\right)\right] u_{p}^{*} D\left(x, y^{*}\right),
\end{aligned}
$$

and simultaneously, the optimum $x$ will solve

$$
\begin{aligned}
w_{x}(z, x) & =\left[C_{x}\left(c^{I}(z, x), c^{V}\left(u_{p}^{*}, y^{*}\right)\right) D\left(x, y^{*}\right)\right. \\
& \left.+C\left(c^{I}(z, x), c^{V}\left(u_{p}^{*}, y^{*}\right)\right) D_{x}\left(x, y^{*}\right)\right] z u_{p}^{*} .
\end{aligned}
$$

Denote the solutions to (12) and (13) by $\hat{z}$ and $\hat{x}$, respectively. Now compare (12) and (13) with (7) and (8). In view of our assumptions and the facts that $u_{p}^{*}>u^{*}$ and $y=y^{*}$, the envelop theorem gives us $\hat{z}<z^{*}$ and $\hat{x}>x^{*}$. In particular, given that $\left(u_{p}^{*}, y^{*}\right)$ is chosen by the victim, no $x<x^{*}$ can be a best response for the injurer. As a result, a set of values $((z, x),(u, y))$, where $x<x^{*}$ and $y=y^{*}$, cannot be a N.E.

An analogous argument shows that a set of values $((z, x),(u, y))$, where $x=x^{*}$ and $y<y^{*}$, cannot be a N.E.

\section{Proof of Proposition 2:}

To see why set of values $\left(\left(z^{*}, x^{*}\right),\left(u^{*}, y^{*}\right)\right)$ cannot be a N.E. under the rule of comparative causation, assume that under the rule there is an equilibrium in which the injurer has chosen $x^{*}$ and the victim has chosen $\left(u^{*}, y^{*}\right)$; otherwise,

nothing is left to prove. Now, since both parties take due care, the choice of optimum $z$ for the injurer will solve

$$
\begin{aligned}
& \max _{z}\left\{w\left(z, x^{*}\right)-\frac{c^{I}\left(z, x^{*}\right)}{c^{I}\left(z, x^{*}\right)+c^{V}\left(u^{*}, y^{*}\right)} C\left(c^{I}\left(z, x^{*}\right), c^{V}\left(u^{*}, y^{*}\right)\right) z u^{*} D\left(x^{*}, y^{*}\right)\right\} \\
& \text { i.e., optimum } z \text { will solve } \\
& \begin{aligned}
w_{z}\left(z, x^{*}\right) & =\frac{c^{I}\left(z, x^{*}\right)}{c^{I}\left(z, x^{*}\right)+c^{V}\left(u^{*}, y^{*}\right)}\left[C_{z}\left(c^{I}\left(z, x^{*}\right), c^{V}\left(u^{*}, y^{*}\right)\right) z\right. \\
& \left.+C\left(c^{I}\left(z, x^{*}\right), c^{V}\left(u^{*}, y^{*}\right)\right)\right] u^{*} D\left(x^{*}, y^{*}\right) \\
& +\frac{c_{z}^{I}\left(z, x^{*}\right) c^{V}\left(u^{*}, y^{*}\right)}{\left[c^{I}\left(z, x^{*}\right)+c^{V}\left(u^{*}, y^{*}\right)\right]^{2}} C\left(c^{I}\left(z, x^{*}\right), c^{V}\left(u^{*}, y^{*}\right)\right) z u^{*} D\left(x^{*}, y^{*}\right)
\end{aligned}
\end{aligned}
$$


A comparison of (9) and (14) shows that in general $z^{*}$ is not a solution of (14), since $\frac{c^{I}\left(z, x^{*}\right)}{c^{I}\left(z, x^{*}\right)+c^{V}\left(u^{*}, y^{*}\right)} \neq 1$. Therefore, the rule cannot attain the efficient care and activity levels as an equilibrium outcome. The inefficiency is inevitable since it is impossible to put the entire accident loss on both the parties at the same time. As a result, it is impossible for a liability rule to create optimal care as well as activity levels incentives simultaneously.

\section{References}

[1] Bar-Gill, Oren, and Ben-Shahar, Omri (2003), 'The Uneasy Case for Comparative Negligence', 5 American Law and Economic Review, 433-469.

[2] Burrows, Paul (1999), 'A deferential role for efficiency theory in analysing causation- based Tort law', 8, European Journal of Law and Economics, 29-49.

[3] Calabresi, Guido (1961), 'Some Thoughts on Risk Distribution and the Law of Torts', 70 Yale Law Journal, 35-46.

[4] Calabresi, Guido (1965), 'The decision for accidents: An approach to non-fault allocation of costs,' 78 Harvard Law Review, 713-745.

[5] Calabresi, Guido (1970), The Costs of Accidents: A Legal and Economic Analysis, New Haven: Yale University Press.

[6] Calabresi, Guido and Cooper, Jeffrey (1996), 'New directions in tort law,' 30 Valparaiso University Law Review, 859-884.

[7] Chung, Tai-Yeong (1993), 'Efficiency of Comparative Negligence: A Game Theoretic Analysis', 22 Journal of Legal Studies, 395-404.

[8] Cooter, Robert D. and Ulen, Thomas S. (1998), Law and Economics, IInd ed., New York, Addison-Wesley.

[9] Cooter, Robert D. and Ulen, Thomas S. (1986), 'An Economic Case for Comparative Negligence', 81 New York University Law Review, 1067-1110.

[10] Dari Mattiacci, G (2002), 'Tort Law and Economics', in Hatzis A. ed., Economic Analysis of Law: A European Perspective, Edward Elgar.

[11] Epstein, Richard A. (1979), 'Causation and Corrective Justice: A Reply to Two Critics', 8 Journal of Legal Studies, 477-504.

[12] Edlin, Aaron S. (1994), 'Efficient Standards of Due Care: Should Courts Find More Parties Negligent under Comparative Negligence?', 14 International Review of Law and Economics, 21-34. 
[13] Emons, Winand (1990), 'Some Recent Developments in the Economic Analysis of Liability Law: An Introduction', 146 Journal of Institutional and Theoretical Economics, 237-248.

[14] Feldman, Allan M. and Singh, Ram. (2009), 'Comparative Vigilance', 11 American Law and Economics Review, 1-28.

[15] Grady, Mark F. (1989), 'Untaken Precautions', 18 Journal of Legal Studies, 139- 156.

[16] Grimley, William (2000), 'Comparative Fault \&Solidary Delictual Obligations: On Further Consideration', 60 Louisiana Law Review 513.

[17] Haddock, David D. and Curran, Christopher (1985): 'An Economic Theory of Comparative Negligence,' 14 Journal of Legal Studies , 49-72.

[18] Honoré, Tony (1997), 'The morality of Tort Law', in Owen, David G. (ed.), Philosophical Foundations of Tort Law, Oxford, Clarendon Press.

[19] Hylton Keith N (2002), 'An asymmetric - information model of litigation', 22 International Review of Law and Economics, 153-175.

[20] Hylton Keith N (2000), 'The Theory of Tort Doctrine and The Restatement of Torts' Boston University School of Law Working Paper Series, Law 83 Economics, No. 00-07.

[21] Jain, Satish K and Singh, Ram, (2002), 'Efficient Liability Rules: Complete Characterization', 75 Journal of Economics, 105-24.

[22] Kahan, Marcel (1989), 'Causation and Incentives to Take Care under the Negligence Rule', 18 Journal of Legal Studies, 427-447.

[23] Kaye, David and Aickin, Mikel (1984), 'A Comment on Causal Apportionment,' 13 Journal of Legal Studies, 191-208.

[24] Kruskal, William (1986), "Terms of Reference: Singular Confusion about Multiple Causation," 15 Journal of Legal Studies, 427-436.

[25] Landes, William M. and Posner, Richard A. (1987), The Economic Structure of Tort Law, Cambridge (MA), Harvard University Press.

[26] Landes, William M. and Posner, Richard A. (1983), 'Causation in Tort Law: An Economic Approach,' 12 Journal of Legal Studies, 109-134.

[27] Lando, Henrik (1997), 'An attempt to incorporate fairness into an economic model of tort law', 17 International Review of Law and Economics, 575-587.

[28] Liao, Yu-Ping and White, Michelle J. (2002), 'No-Fault for Motor Vehicles: An Economic Analysis', 4 American Law and Economics Review, 258-294.

[29] Marks, Stephen V. (1994), 'Discontinuities, Causation, and Grady's Uncertainty Theorem', 23 Journal of Legal Studies, 287-301. 
[30] Miceli, Thomas J. (1997), Economics of the Law: Torts, Contracts, Property, Litigation, Oxford, Oxford University Press.

[31] Parisi, Francesco (1992), Liability for Negligence and Judicial Discretion (2nd ed.), Berkeley, University of California Press.

[32] Parisi, Francesco (2001), 'Genesis of Liability in Ancient Law', 3 American Law and Economics Review, 82-124.

[33] Parisi, Francesco and Fon, Vincy (2004), 'Comparative Causation', 6, American Law and Economics Review, 345-368.

[34] Parisi, Francesco and Fon, Vincy (2005), "Causation and Responsibility: The Compensation Principle from Grotius to Calabresi" 64 Maryland Law Review, 108-135

[35] Polinsky, A. Mitchell. (1989), An Introduction to Law and Economics, 2nd ed, Boston, Little, Brown and Co.

[36] Polinsky, A. Mitchell and Che, Yeon-Koo (1991), ?Decoupling Liability: Optimal incentives for Care and Litigation?, 22 Rand Journal of Economics, 562-570.

[37] Rea, Samuel A. Jr. (1987): 'The Economics of Comparative Negligence,' 7 International Review of Law and Economics, 149-162.

[38] Rizzo, Mario J. and Arnold, Frank S. (1980), 'Causal Apportionment in the Law of Torts: an Economic Theory,' 80 Columbia Law Review, 1399-1429.

[39] Rizzo, Mario J. and Arnold, Frank S. (1986), 'Causal Apportionment: Reply to the Critics,' 15 Journal of Legal Studies, 219-226.

[40] Rubinfeld, Daniel L. (1987), 'The Efficiency of Comparative Negligence', 16 Journal of Legal Studies, 375-394.

[41] Schafer, Hans-Bernd (2000), 'Tort Law: General', in Encyclopedia of Law and Economics, Bouckaert, Boudewijn and De Geest, Gerrit (eds.), Cheltenham, Edward Elgar, 682-734.

[42] Schweizer, Urs (2009), 'Legal damage for losses of chances', 29 International Review of Law and Economics, 153-160.

[43] Shavell, Steven (1987), Economic Analysis of Accident Law, Cambridge (MA), Harvard University Press.

[44] Singh, Ram (2006), 'On the Existence and Efficiency of Equilibria under Liability Rules,' NBER Working Paper number 12625.

[45] Singh, Ram (2007 a), 'Causation-consistent Liability, Economic Efficiency and the Law of Torts' 27 International Review of Law and Economics, pp. 179-203. 
[46] Singh, Ram (2007 b), 'Comparative Causation and Economic Efficiency: When activity levels are constant' 3, Review of Law and Economics, pp 383-406.

[47] Strassfeld, Robert (1992), 'Causal Comparisons', 60 Fordham Law review, 913- 951.

[48] Wright, Richard W. (1987), 'The Efficiency Theory of Causation and Responsibility: Unscientific Formalism and False Semantics', 63 Chicago-Kent Law Review, 553-578.

[49] Van Wijck, Peter and Winters, Jan Kees (2001), 'The Principle of Full Compensation in Tort Law', 11 European Journal of Law and Economics, 319-332.

[50] Yoshihsa, Nomi (1999), "Environmental Liability in Japan", in, Ewould Hondius ed. 1999, Modern Trends in Tort Law, Kluwer Academic Publishers.

[51] Yu, Li (2000), "Book Review: Modern Trends in Tort Law: Dutch and Japanese Law Compared", 6 Columbia Journal of European Law 147-148. 